\title{
The Micromolar Zinc-Binding Domain on the NMDA Receptor Subunit NR2B
}

\author{
Julie Rachline, ${ }^{*}$ Florent Perin-Dureau, ${ }^{\star}$ Anne Le Goff, Jacques Neyton, and Pierre Paoletti \\ Laboratoire de Neurobiologie, Centre National de la Recherche Scientifique Unité Mixte de Recherche 8544, Ecole Normale Supérieure, 75005 Paris, France
}

\begin{abstract}
Eukaryotic ionotropic glutamate receptor subunits possess a large N-terminal domain (NTD) distinct from the neighboring agonistbinding domain. In NMDA receptors, the NTDs of NR2A and NR2B form modulatory domains binding allosteric inhibitors. Despite a high sequence homology, these two domains have been shown to bind two ligands of strikingly different chemical nature. Whereas the NTD of NR2A binds zinc with high (nanomolar) affinity, the NTD of NR2B binds the synthetic neuroprotectant ifenprodil and its derivatives. Using both NTD-mutated/deleted receptors and isolated NTDs, we now show that the NTD of NR2B, in contrast to NR2C and NR2D, also binds zinc, but with a lower affinity. Furthermore, we present evidence that zinc and ifenprodil compete for an overlapping binding site. This modulatory binding site accounts for the submicromolar zinc inhibition of NR1/NR2B receptors. Given that zinc is accumulated and released at many glutamatergic synapses in the CNS, these findings suggest that zinc is the endogenous ligand of the NTD of both NR2A and NR2B, the two major NR2 subunits. Thus, NMDA receptors contain zinc sensors capable of detecting extracellular zinc over a wide concentration range depending on their NR2 subunit composition. The coexistence of subunit-specific zinc-binding sites of high (nanomolar) and low (micromolar) affinity on NMDA receptors raises the possibility that zinc exerts both a tonic and a phasic control of membrane excitability.
\end{abstract}

Key words: glutamate receptors; NMDA; zinc; ifenprodil; LIVBP; synaptic transmission

\section{Introduction}

Among ionotropic glutamate receptors (iGluRs), NMDA receptors are endowed with two functional properties, high Ca permeability and strong voltage dependence conferred by $\mathrm{Mg}$ pore blockade, that are critical in processes such as development of the nervous system and its plasticity. NMDA receptors have also been implicated in a number of neurological disorders. Overstimulation of NMDA receptors because of an excess of glutamate, as encountered during cerebral ischemia or epilepsia, has long been known to promote neuronal death (Kemp and McKernan, 2002). In contrast, a deficit in NMDA receptor activity is now emerging as a central feature in the pathophysiology of schizophrenia (Moghaddam, 2003). Setting the appropriate level of NMDA receptor activity thus seems to be of primary importance.

Structural studies of iGluRs have revealed that these receptors are made of four subunits sharing a common architecture (Mayer and Armstrong, 2004). Each subunit comprises distinct domains that each fulfills a precise function. The membrane domain, which contains the ion pore and selectivity filter, shows sequence

Received June 30, 2004; revised Nov. 11, 2004; accepted Nov. 11, 2004.

This work was supported by the Ministère de la Recherche (J.R.), Assistance Publique des Hôpitaux de Paris (F.P.-D.), and Institut National de la Santé et de la Recherche Médicale (P.P.). We thank Stéphane Dieudonné for advice concerning the competition experiments and Chris Hatton, James Kew, and Philippe Ascher for comments on this manuscript. We also thank Sanofi-Synthélabo for the gift of ifenprodil.

*J.R. and F.P.-D. contributed equally to this work.

Correspondence should be addressed to Dr. Pierre Paoletti, Laboratoire de Neurobiologie, Centre National de la Recherche Scientifique Unité Mixte de Recherche 8544, Ecole Normale Supérieure, 46 rue d’Ulm, 75005 Paris, France. E-mail:paoletti@biologie.ens.fr.

D01:10.1523/JNEUROSCI.3967-04.2005

Copyright $\odot 2005$ Society for Neuroscience $\quad$ 0270-6474/05/250308-10\$15.00/0 and functional homology with $\mathrm{K}$ channels. The agonist-binding domain, the structure of which has been solved in the case of the AMPA receptor subunit GluR2 (Armstrong et al., 1998) and of the NMDA receptor subunit NR1 (Furukawa and Gouaux, 2003), displays structural and functional similarities with some bacterial periplasmic binding proteins (PBPs). The recent discovery of the prokaryotic receptor GluR0 (Chen et al., 1999) shows that iGluRs originated in bacteria by the association of an ion channel module with a module capable of agonist binding. Eukaryotic iGluRs further increased in complexity after the addition of two elements: (1) a third transmembrane segment connected to a C-terminal domain, allowing for intracellular interaction with cytoskeletal and signal transduction molecules; and (2) a large ( $\sim 400 \mathrm{aa}) \mathrm{N}$-terminal domain (NTD), also related in sequence to a PBP [leucine-isoleucine-valine binding protein (LIVBP)] (O'Hara et al., 1993; Paoletti et al., 2000). In both NMDA and AMPA/kainate receptors, the NTD is a major, but not the sole, determinant of subtype-specific subunit assembly (Leuschner and Hoch, 1999; Ayalon and Stern-Bach, 2001; Meddows et al., 2001). Recent studies have also shown that, in certain NMDA receptor subunits, the NTD modulates ion channel gating through binding of extracellular allosteric modulators: $\mathrm{Zn}$ in the case of the NR2A subunit (Choi and Lipton, 1999; Fayyazuddin et al., 2000; Low et al., 2000; Paoletti et al., 2000) and the noncompetitive synthetic antagonist ifenprodil and its derivatives in the case of NR2B (Perin-Dureau et al., 2002; Malherbe et al., 2003). Because $\mathrm{Zn}$ is known to be concentrated and released during activity at many glutamatergic synapses in the CNS (Frederickson et al., 2000), it appears to be a likely candidate as the endogenous ligand of the NTD of NR2A. But what about endog- 
enous ligands, if any, of other iGluR subunits and, in particular, of the NMDA receptor subunit NR2B, which contains an NTD functionally coupled to the gating machinery? We now present evidence that the NTD of NR2B, but not that of NR2C and NR2D, forms a specialized Zn-binding site.

\section{Materials and Methods}

Molecular biology. The pcDNA3-based expression plasmids (for rat NR1-1a, rat NR2A, mouse $\epsilon 2$, and rat NR2C), the mutagenesis strategy, the sequencing, and the RNA synthesis have been described previously (Paoletti et al., 1997, 2000; Perin-Dureau et al., 2002). The rat NR2D cDNA (splice variant NR2D-A) was subcloned into the pcDNA3-based plasmid from the NR2D-SP-Ex1 plasmid (a gift from Thomas Kuner, Max-Planck Institute for Medical Research, Heidelberg, Germany). The NTD-deleted NR2 subunits were constructed by replacing the endogenous peptide signal sequence by a modified signal sequence of influenza hemagglutinin (HA), followed by an eight-residue "Flag" epitope [as originally introduced in the NR2A' $(\Delta \mathrm{N} 1-3)$ tr subunit] (Fayyazuddin et al., 2000). The modified influenza HA signal sequence is a cleavable signal peptide that has been shown to enhance membrane insertion and functional expression of certain membrane proteins (Guan et al., 1992). So, the N-terminal sequences of the four NTD-deleted NR2 subunits are as follows:

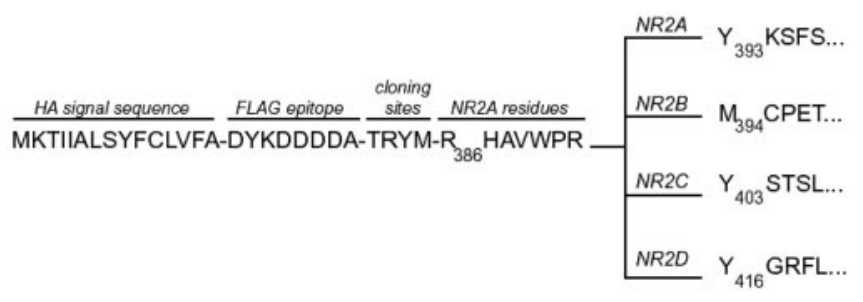

Compared with wild-type receptors, both the yield and rate of expression of the NR2-deleted receptors were markedly decreased. Thus, whereas large (more than a few hundreds of nanoamperes) currents were usually obtained $1 \mathrm{~d}$, for NR2A- and NR2B-containing receptors, or $2 \mathrm{~d}$, for NR2C- and NR2D-containing receptors, after oocyte injection for wildtype receptors, at least $3 \mathrm{~d}$ of expression were usually required for NR2deleted receptors. For NTD-deleted NR2A- and NR2B-containing receptors, currents up to a few microamperes were obtained in some oocytes. For NTD-deleted NR2C- and NR2D-containing receptors, currents were much smaller with maximal values $\sim 80$ and $150 \mathrm{nA}$, respectively. In trying to increase the expression level, all four NR2 NTD-deleted constructs, as well as wild-type NR2C and NR2D subunits, were subcloned into the mammalian expression vector pRK5 (a gift from Pari Malherbe, Hoffmann-La Roche, Basel, Switzerland). The use of this vector increased the relative proportion of oocytes that showed expression and the rate at which they express. However, the maximal currents were not significantly larger than the ones obtained with the pcDNA3-based vectors. In most experiments, the pRK5-based, rather than the pcDNA3based, plasmids were used. All NR2B point mutants were expressed as cRNAs.

Biochemistry. Isolated NR2B NTDs (full length and truncated) were produced and purified as described previously (Perin-Dureau et al., 2002). In trypsinolysis experiments, purified isolated domains were preincubated with ifenprodil or zinc for $5 \mathrm{~min}$ before the addition of trypsin. These experiments were performed in the following buffer (in mM): 200 $\mathrm{NaCl}$ and 20 Tris, $\mathrm{pH}$ 7.5. The estimated ratio of protease/protein in each reaction is 1:500 for NTD-D101A and 1:150 for wild-type $\mathrm{NTD}_{\mathrm{tr}}$ and $\mathrm{NTD}_{\mathrm{tr}}-\mathrm{H} 127 \mathrm{~A}$, because these latter domains are more resistant to trypsin digestion. Trypsin digestion was stopped by the addition of the SDScontaining loading buffer. Samples were analyzed on 12\% SDS-PAGE gels as described by Perin-Dureau et al. (2002). As revealed on such gels, the produced domains are not completely pure polypeptides because additional bands of molecular weights smaller than expected are also seen, but these additional bands are always of lower intensity (see Fig. 7) (Perin-Dureau et al., 2002).

Electrophysiology. Recombinant NMDA receptors were expressed in Xenopus laevis oocytes after coinjection of cDNAs (at $10 \mathrm{ng} / \mu \mathrm{l}$; nuclear injection) or cRNAs (at $100 \mathrm{ng} / \mu \mathrm{l}$ ) coding for wild-type NR1-1a and various NR2 subunits. Oocytes were prepared, injected, voltage clamped, and superfused as described previously (Paoletti et al., 1995, 1997). The standard external solution contained (in mM) $100 \mathrm{NaCl}, 0.3 \mathrm{BaCl}_{2}$, and 5 HEPES. The $\mathrm{pH}$ was adjusted to 7.3 with $\mathrm{KOH}$. For receptors displaying an intermediate $\mathrm{Zn}$ sensitivity $\left(\mathrm{IC}_{50} \geq \mathrm{IC}_{50}\right.$ of wild-type NR1/NR2B receptors), $\mathrm{Zn}$ was not buffered, and $\mathrm{Zn}$-free reference solutions were made by adding $10 \mu \mathrm{M}$ diethylenetriamine-pentaacetic acid (DTPA) (to chelate trace amounts of contaminant $\mathrm{Zn}$ ) (Paoletti et al., 1997) to the agonist-free control solution and to the agonist-added zero-Zn-added solution. For zinc concentrations $>100 \mu \mathrm{M}$, the $\mathrm{pH}$ was readjusted to 7.3. For receptors displaying a high $\mathrm{Zn}$ sensitivity $\left(\mathrm{IC}_{50} \leq \mathrm{IC}_{50}\right.$ of wild-type NR1/NR2B receptors), $\mathrm{Zn}$ was buffered in the nanomolar range using tricine [ $N$-tris(hydroxymethyl)methylglycine], as described by Fayyazuddin et al. (2000). NMDA currents were induced by simultaneous application of saturating concentrations of L-glutamate and glycine (100 $\mu \mathrm{M}$ each) and usually recorded at $-60 \mathrm{mV}$. Voltage-ramps $(2 \mathrm{sec},-70$ to $+50 \mathrm{mV}$ ) were used in some experiments (see below). All experiments were performed at room temperature $\left(18-24^{\circ} \mathrm{C}\right)$. Error bars represent the SD of the mean relative currents.

Data analysis. Data were collected and analyzed using pClamp 8.0 (Axon Instruments, Foster City, CA). For the majority of Zn dose-inhibition curves, currents were measured at $+50 \mathrm{mV}$, a potential at which the voltage-dependent component of $\mathrm{Zn}$ inhibition (pore block) is virtually absent (Paoletti et al., 1997). NMDA receptor currents at $+50 \mathrm{mV}$ were obtained using voltage ramps and after capacitive and leakage current subtraction. Some $\mathrm{Zn}$ inhibition curves were also obtained at -60 $\mathrm{mV}$ for receptors having a $\mathrm{Zn}$ sensitivity in the nanomolar range (in that range, there is no voltage-dependent component of inhibition). For wildtype NR1/NR2C and NR1/NR2D receptors, Zn inhibition curves were obtained at both voltages $(-60$ and $+50 \mathrm{mV})$, and no significant difference was found between these two potentials [for NR1/NR2D receptors, the $\mathrm{Zn} \mathrm{IC}_{50}$ value is $8.4 \mu \mathrm{M}(n=6)$ at $-60 \mathrm{mV}$ and $9.2 \mu \mathrm{M}(n=5)$ at +50 $\mathrm{mV}$; data not shown for NR1/NR2C receptors]. Given the low expression level of NR1/NR2D- $\Delta$ NTD receptors, voltage ramps were not attempted on these receptors, and all currents were measured at a steady potential of $-60 \mathrm{mV}$. Thus, Figure $3 \mathrm{C}$ compares the $\mathrm{Zn}$ dose-response curves of wild-type NR1/NR2D receptors and NR1/NR2D- $\Delta$ NTD receptors obtained at $-60 \mathrm{mV}$. Data were fitted using SigmaPlot 8.0 (SSPS, Chicago, IL). When $\mathrm{Zn}$ was buffered using tricine (see above), the experimental data points were fitted with the following Hill equation (Eq. 1): $I_{\mathrm{Zn}}$ l $I_{\text {control }}=1-a /\left(1+\left(\mathrm{IC}_{50} /[\mathrm{Zn}]\right)^{\mathrm{nH}}\right)$, where $I_{\mathrm{Zn}} / I_{\text {control }}$ is the mean relative current, $[\mathrm{Zn}]$ is the concentration of free $\mathrm{Zn}, \mathrm{nH}$ is the Hill coefficient, $a$ is the maximal inhibition, and $\mathrm{IC}_{50}$ is the concentration of $\mathrm{Zn}$ producing $50 \%$ of the maximal inhibition. $\mathrm{IC}_{50}, a$, and $\mathrm{nH}$ were fitted as free parameters. When $\mathrm{Zn}$ was not buffered (i.e., free $\mathrm{Zn}=$ added $\mathrm{Zn}+$ contaminant $\mathrm{Zn}$ ), the level of contaminant $\mathrm{Zn}$ was first estimated using the following Hill-derived equation (Eq. 2): $I_{\mathrm{Zn}} / I_{\text {control }}=$ $1-a /\left(1+\left(\mathrm{IC}_{50} /[\mathrm{Zn}+b]\right)^{\mathrm{nH}}\right)$, where $b$ represents the contaminant $\mathrm{Zn}$ concentration, and $\mathrm{Zn}$ is the added $\mathrm{Zn}$ concentration. After estimating the $b$ value (usually between 100 and $200 \mathrm{~nm}$ ), Zn concentrations were corrected for the estimated contaminant concentration, and data points were then refitted with Equation 1. For wild-type NR1/NR2B receptors, no difference was observed between fits of data points obtained with or without tricine $\left[\mathrm{Zn} \mathrm{IC}{ }_{50}\right.$ values of $770 \mathrm{~nm}(n=3)$ and $760 \mathrm{~nm}$, respectively] (see Fig. 1).

Chemicals. All salts (except $\mathrm{ZnCl}_{2}$ ) were obtained from Prolabo (Paris, France) and were of "Normapure" grade. All other chemicals were purchased from Sigma (Saint Quentin Fallavier, France). Zn was added as chloride salts $\left(\mathrm{ZnCl}_{2}, \mathrm{ACS}\right.$ reagent quality) by dilution from $1 \mathrm{M}$ or 100 mM stock solutions prepared in $0.1 \mathrm{M} \mathrm{HCl}$. Ifenprodil (a gift from Bernard Scatton, Sanofi-Synthélabo, Bagneux, France) was prepared as described by Perin-Dureau et al. (2002). L-Glutamate (L-glutamic acid monosodium salt) and glycine were prepared as $100 \mathrm{~mm}$ stock solutions in double-distilled water. Tricine was directly diluted to the final concen- 


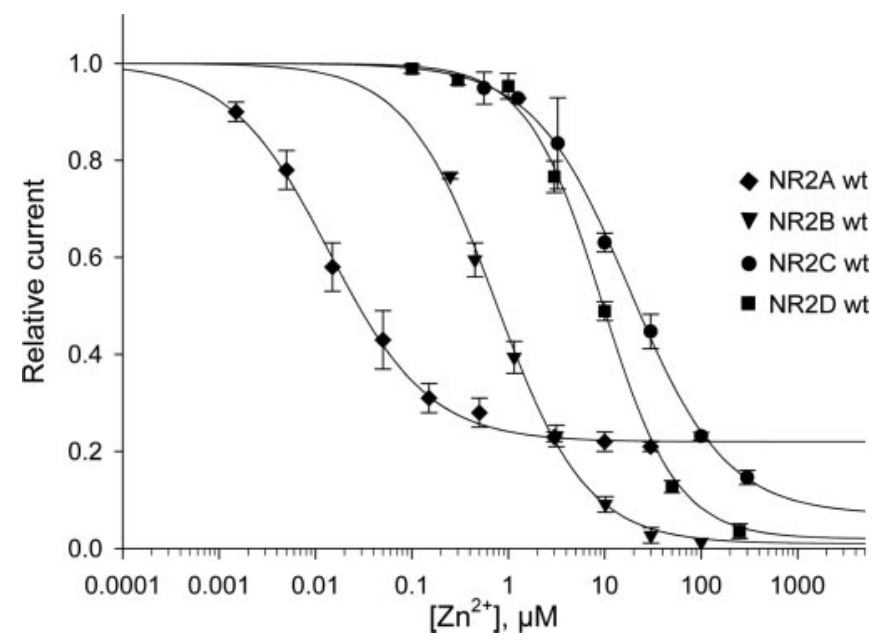

Figure 1. The Zn sensitivity of recombinant NMDA receptors is NR2 specific. Zn doseresponse curves of diheteromeric NR1/NR2 receptors expressed in Xenopus 0ocytes are shown. Currents were elicited by saturating concentrations of glutamate and glycine (100 $\mu \mathrm{m} \mathrm{each})$ and measured at $+50 \mathrm{mV}$, at which voltage-dependent $\mathrm{Zn}$ block is virtually absent. For NR1/NR2A receptors, tricine was used to buffer $Z n$. For other receptor subtypes, Zn was not buffered, and Zn concentrations were corrected for contaminating Zn (for NR1/NR2B receptors, very similar curves were obtained using tricine-buffered solutions; see Materials and Methods). The curves represent least-square fits to the data point with the Hill equation. The estimated values of $\mathrm{I}_{50}$, maximal inhibition, and Hill coefficient are as follows: $16 \mathrm{~nm}, 0.77$ and 0.9 for NR1/NR2A receptors; $760 \mathrm{~nm}, 1.0$ and 0.9 for NR1/NR2B receptors; $18 \mu \mathrm{m}, 0.93$ and 0.9 for NR1/NR2C receptors; $9.2 \mu \mathrm{m}, 1.0$ and 1.2 for NR1/NR2D receptors. Each data point is the mean value from at least three different oocytes.

tration, and the $\mathrm{pH}$ was readjusted to 7.3. DTPA was prepared as a 100 mM stock solution in double-distilled water.

\section{Results}

Zinc sensitivity of recombinant NMDA receptors varies over three orders of magnitude depending on the type of NR2 subunit expressed

Zinc inhibits NMDA receptor activity through a dual mechanism, a voltage-dependent channel block and a voltageindependent reduction in probability of channel opening (Mayer et al., 1989; Christine and Choi, 1990; Legendre and Westbrook, 1990). The potency of the voltage-independent zinc inhibition (hereafter referred to as $\mathrm{Zn}$ inhibition) is known to strongly depend on the type of NR2 subunit expressed, being of particularly high affinity for NR2A-containing receptors (Williams, 1996; Chen et al., 1997; Paoletti et al., 1997; Traynelis et al., 1998). The comparison of the Zn sensitivity of all four NR1/NR2 diheteromeric recombinant receptors expressed in Xenopus oocytes is shown in Figure 1. Zn sensitivity decreases in the order NR1/ $\mathrm{NR} 2 \mathrm{~A} \gg \mathrm{NR} 1 / \mathrm{NR} 2 \mathrm{~B}>\mathrm{NR} 1 / \mathrm{NR} 2 \mathrm{D} \approx \mathrm{NR} 1 / \mathrm{NR} 2 \mathrm{C}$ with the $\mathrm{Zn}$ $\mathrm{IC}_{50}$ value ranging from a low nanomolar level for the most sensitive NR1/NR2A receptors to a low micromolar level for the least sensitive NR1/NR2D and NR1/NR2C receptors. In between these two extremes, NR1/NR2B appears to have an intermediate $\mathrm{Zn}$ sensitivity, with an $\mathrm{IC}_{50}$ value in the submicromolar level. Previous studies have shown that the high-affinity $\mathrm{Zn}$ inhibition of NR1/NR2A is attributable to Zn binding to the NTD of NR2A and that a few residues in this domain are closely associated with the $\mathrm{Zn}$ coordination site (Choi and Lipton, 1999; Fayyazuddin et al., 2000; Low et al., 2000; Paoletti et al., 2000). In contrast, the zinc-binding sites accounting for the lower $\mathrm{Zn}$ sensitivities observed with NR2B/C/D-containing receptors have not yet been identified. The fact that the NR2 NTDs share an overall high sequence similarity ( $>58 \%$ according to ClustalW) suggested that the NTDs of NR2B/C/D may also contain Zn-binding sites. Accordingly, several of the key NR2A residues controlling highaffinity $\mathrm{Zn}$ inhibition are conserved in the NTDs of the other NR2 subunits (in particular, D102, D105, and H128), with NR2B having the highest degree of conservation (see Fig. 5). However, the large difference in apparent $\mathrm{Zn}$ affinities between receptors containing NR2A and other NR2 subunits ( $>50$-fold) could alternatively indicate that in these latter subunits, $\mathrm{Zn}$ binds in domains other than the NTDs. In addition, it has been proposed that Zn inhibition of NR2A- and NR2B-containing receptors involves different mechanisms (Traynelis et al., 1998; Low et al., 2000) (see Discussion).

\section{The NTD of NR2B controls Zn inhibition of NR1/NR2B receptors}

To look for a possible involvement of the NTDs of NR2B/C/D in the $\mathrm{Zn}$ sensitivity of NMDA receptors, we decided to construct NTD-deleted NR2 subunits. We had previously shown that the NTD is not required for expression of functional receptors because the NR2A subunit truncated for its entire NTD could still incorporate into functional channels when coexpressed with NR1 [see the construct NR2A' $(\Delta \mathrm{N} 1-3)$ tr described by Fayyazud-

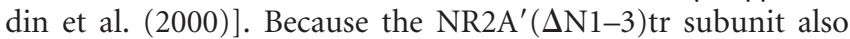
differs from the parental NR2A wild-type subunit at positions outside the N-terminal region (Fayyazuddin et al., 2000), we first constructed new NTD-deleted NR2A subunits based on a pure wild-type NR2A template. However, none of these initial constructs (differing in the truncation length) yielded functional receptors when coexpressed with wild-type NR1. It was only after replacing the endogenous peptide signal sequence with a modified influenza HA signal sequence (a sequence known to enhance membrane insertion and originally introduced in the $\mathrm{NR}_{2} \mathrm{~A}^{\prime}(\Delta \mathrm{N} 1-3) \operatorname{tr}$ subunit) (see Materials and Methods) that we finally obtained a functional NTD-deleted NR2A subunit. Using the same approach, functional NTD-deleted NR2B, NR2C, and NR2D subunits were also obtained (see Materials and Methods for deletion boundaries).

As expected, deleting the NTD of NR2A virtually eliminated high-affinity $\mathrm{Zn}$ inhibition with a mean inhibition produced by $200 \mathrm{~nm} Z \mathrm{Zn}$ of $4 \pm 1 \%(n=3)$ compared with $72 \pm 3 \%(n=6)$ for wild-type NR1/NR2A receptors (Fig. $2 A$ ). Zn sensitivity of NR2B-containing receptors was also strongly decreased by the deletion of the NR2B NTD with a mean inhibition produced by 1 $\mu \mathrm{M} \mathrm{Zn}$ of $7 \pm 3 \%(n=10)$ compared with $60 \pm 2 \%(n=4)$ for wild-type NR1/NR2B receptors (Fig. $2 B$ ). In contrast, Zn sensitivity of NR1/NR2D receptors was only slightly affected by the deletion of the NR2D NTD because Zn inhibition produced by 20 $\mu \mathrm{M} Z n$ decreased from $75 \pm 1 \%(n=5)$ for wild-type NR1/NR2D receptors to $61 \pm 3 \%(n=5)$ for receptors containing NTDdeleted NR2D subunits (Fig. 2C). For receptors containing NTDdeleted NR2C subunits, a large variability of the effects was observed that may be attributable to the very small amplitude of the agonist-induced currents ( $80 \mathrm{nA}$ maximum; less than twice the usual leak current amplitude). However, there was no indication of a drastic change in $\mathrm{Zn}$ sensitivity [mean inhibition by $30 \mu \mathrm{M} \mathrm{Zn}$ of $43 \pm 29 \%(n=6)$ compared with an inhibition of $55 \pm 3 \%$ $(n=5)$ at wild-type NR1/NR2C receptors].

Full $\mathrm{Zn}$ concentration-response curves obtained on wild-type and NTD-deleted receptors are compared in Figure 3. Deletion of the NTD of NR2A increased the $\mathrm{Zn} \mathrm{IC}_{50}$ value by $>500$-fold, from the low nanomolar range to the low micromolar range. Deletion of the NTD of NR2B produced an $\sim 16$-fold rightward shift in Zn sensitivity. Conversely, transplanting the NTD of 


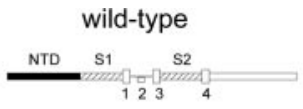

A

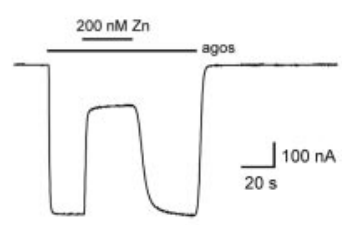

B

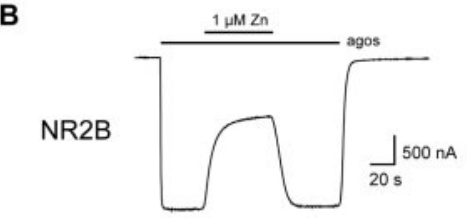

C

NR2D

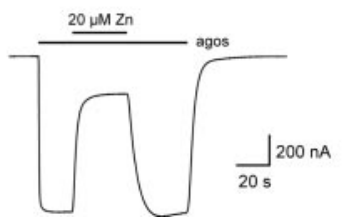

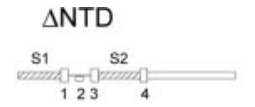
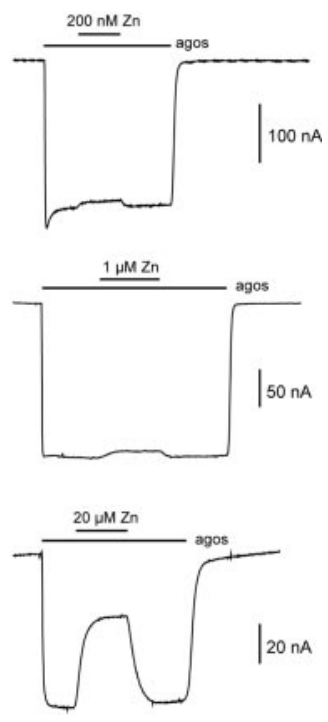

Figure 2. Differential effects of NR2 NTD deletions on Zn sensitivity. Each trace shows the inhibition by Zn of NMDA NR1/NR2 receptors containing either wild-type (left) or NTD-deleted ( $\triangle$ NTD; right) NR2 subunits. Recordings were made at $-60 \mathrm{mV}$. The bars above the current traces indicate the duration of agonist (agos) and $\mathrm{Zn}$ applications. Diagrams of wild-type and deleted NR2 constructs are shown at the top (S1 and S2, agonist binding domains; 1, 3, and 4, transmembrane segments; 2 , pore loop). $A$, A concentration of $200 \mathrm{~nm} \mathrm{Zn} \mathrm{(buffered} \mathrm{with} \mathrm{tricine)}$ on wild-type and deleted NR1/NR2A receptors. $B, A$ concentration of $1 \mu \mathrm{m} Z n$ on wild-type and deleted NR1/NR2B receptors. C, A concentration of $20 \mu \mathrm{m} Z n$ on wild-type and deleted NR1/ NR2D receptors.

NR2B on the NTD-deleted NR2A subunit produced a leftward shift in Zn sensitivity, such that the Zn sensitivity of the chimeric $\mathrm{NR} 1 / \mathrm{NR} 2 \mathrm{~A}$ (NTD 2B) receptors is close to that of wild-type NR1/ NR2B receptors (Fig. 3D) (Paoletti et al., 2000). In contrast, as already suggested by the current traces shown in Figure $2 C$, deletion of the NTD of NR2D had a very minor effect on Zn sensitivity $\left(<1.5\right.$-fold shift in the $\mathrm{Zn} \mathrm{IC}_{50}$ value) (Fig. $\left.3 \mathrm{C}\right)$. It is noteworthy that all three NR2A, NR2B, and NR2D NTD-deleted constructs retain a residual, voltage-independent $\mathrm{Zn}$ inhibition with an identical $\mathrm{IC}_{50}$ value $(\sim 12 \mu \mathrm{M})$, regardless of the type of NR2 subunit expressed. This suggests that all NMDA receptor subtypes possess a common low-affinity inhibitory Zn-binding site located outside of both the NR2 NTDs and the pore region. There is presently no other indication regarding the location of this common $\mathrm{Zn}$-binding site. The present results also suggest that $\mathrm{Zn}$ binding to this latter site, and not to the NTD of NR2D, underlies the $\mathrm{Zn}$ sensitivity of NR1/NR2D receptors. In contrast, they demonstrate that the intermediate (submicromolar) Zn sensitivity of NR1/NR2B receptors is controlled by the NTD of the NR2B subunit, an effect mirroring that described with the NTD of NR2A in NR1/NR2A receptors.

\section{Screening for mutations affecting $\mathrm{Zn}$ inhibition of NR1/NR2B receptors}

The above results suggest that the NTD of NR2B may form a Zn-binding site. Using a point mutation approach, we looked for residues of the NR2B NTD that may participate in the formation of a $\mathrm{Zn}$-binding site. We first focused on residues located at homologous positions of the key residues of NR2A involved in highaffinity $\mathrm{Zn}$ binding. Among the six critical NR2A residues (H44, D102, D105, H128, K233, and E266) (Paoletti et al., 2000), only

four are strictly conserved in NR2B (D101, D104, H127 and K234) (see the alignment of Fig. 5). As shown in Figure 4, mutating (to alanine) individually, D101 or H217 in NR2B significantly decreased the Zn sensitivity of NR1/NR2B receptors, shifting the $\mathrm{Zn} \mathrm{IC}_{50}$ value more than sixfold compared with wild-type receptors. It is worth noting that these shifts are markedly lower than those previously observed on the NR2A high-affinity zincbinding site ( 300-fold shift) (Choi and Lipton, 1999; Fayyazuddin et al., 2000; Low et al., 2000; Paoletti et al., 2000). However, as already discussed by Fayyazuddin et al. (2000), changes in apparent $\mathrm{Zn}$ sensitivity induced by "strong" mutations are limited by the presence of the low-affinity $\mathrm{Zn}$ inhibitory binding site common to all NR2 NTD-deleted receptors (see above). Accordingly, we expected that point mutations in the NR2B NTD would shift the $\mathrm{Zn} \mathrm{IC} \mathrm{IC}_{50}$ value by a factor of 15 at most. In contrast to the D101A and H127A mutations, substitutions NR2B-D104A or K234A did not significantly affect the receptor $\mathrm{Zn}$ sensitivity (data not shown). Thus, NR2B residues D101 and H127 (but not D104 and K234) are important determinants of the Zn sensitivity of NR1/NR2B receptors. Because D101 is conserved both in NR2C (D110) and NR2D (D116), and H127 is conserved in NR2D (H142) (but not in NR2C) (Fig. 5), we tested the effect of the mutations NR2C-D110A, NR2D-D116A, and NR2D-H142A on the $\mathrm{Zn}$ sensitivity of NR1/NR2C or NR1/NR2D receptors. For all three mutations, no significant difference relative to wild-type receptors was observed [ $\mathrm{IC}_{50}$ values of $20 \mu \mathrm{M}(n=3)$ for NR2CD110A, 7.4 $\mu \mathrm{M}(n=3)$ for NR2D-D116A, and $9.3 \mu \mathrm{M}(n=3)$ for NR2D-H142A; data not shown], supporting our conclusion based on deletion experiments that there is no apparent involvement of the NTDs of NR2C and NR2D in the Zn modulation.

We also assessed Zn sensitivity of the series of NR2B NTD point mutants that we had previously produced during the course of our study on the NR2B-specific ifenprodil-binding site (Perin-Dureau et al., 2002). These mutations had been introduced in regions known in the LIVBP-like domains of other proteins to line a central cleft that directly interacts with the ligands (Perin-Dureau et al., 2002) (Fig. 5, boxes). In the present study, mutants were screened by measuring the inhibition of agonistinduced currents at three concentrations of $\mathrm{Zn}: 0.1 \mu \mathrm{M} ; 1 \mu \mathrm{M}$, a concentration close to the $\mathrm{IC}_{50}$ value; and $10 \mu \mathrm{M}$, a nearly saturating concentration at wild-type NR1/NR2B receptors. No significant effect (less than threefold shift in the estimated $\mathrm{IC}_{50}$ value) was observed for 30 of 40 mutants: V39A, I40A, L41A, T44A, S45A, D46A, V48A, D102A, D104A, Q105A, E106A, I126A, S130A-S131A, S149A, I150A, E151A, F176A, Y179A, Q180A, D181A, K234A, E235A, E236A, S260A, L261A, V262A, A263S, G264A, T266A, and D267A (data not shown). For those mutants (10) that showed a significant difference with the wildtype receptors, full concentration-response curves of $\mathrm{Zn}$ antagonism were constructed. All mutants decreased Zn sensitivity, with the noticeable exception of V42A, which markedly increased $\mathrm{Zn}$ sensitivity (Fig. $4 \mathrm{~A}$ and see below); the deduced values of $\mathrm{IC}_{50}$ were (in $\mu \mathrm{M}$ ): 0.17 for V42A, 2.6 for G43A, 2.8 for E47A, 5.7 for D101A, 3.7 for T103A, 4.9 for H127A, 2.7 for Y175A, 2.5 for F182A, 2.6 for T233A, and 3.1 for D265A. Thus, the two mutations (apart from V42A) that had the most pronounced effect on Zn sensitivity were D101A and H127A, which were first identified given their homologous position to residues of NR2A intimately involved in the high-affinity NR2A-specific Zn-binding site. Other strong mutations included E47A and D265A, which are located in regions homologous to putative loops of NR2A containing key residues for the high-affinity $\mathrm{Zn}$ inhibition (Fig. 5). Interestingly, it is in the putative loop $\beta 1 / \alpha 1$ that we found the 
only mutation, V42A, that produced a gain-of-function phenotype. These findings reveal that the first loop of the NR2B NTD plays a critical role in setting the $\mathrm{Zn}$ sensitivity of NR1/NR2B receptors.

We have previously shown that a number of residues in the NTD of NR2B control ifenprodil inhibition of NR1/NR2B receptors (Perin-Dureau et al., 2002). We now present evidence that some residues in this domain also control $\mathrm{Zn}$ inhibition. To what extent are the $\mathrm{Zn}$ and ifenprodil determinants overlapping? Figure $4 B$ compares the effect of these critical mutants on $\mathrm{Zn}$ and ifenprodil inhibition. The mutations can be subdivided into three groups according to the degree of specificity toward each antagonism (Fig. 5): mutations affecting $\mathrm{Zn}$ inhibition only (e.g., H127A and D265A), mutations affecting ifenprodil inhibition only (e.g., D104A and F176A), and mutations affecting both (e.g., V42A, D101A, F182A, and T233A). The fact that some mutations discriminate between $\mathrm{Zn}$ and ifenprodil inhibitions suggests that the corresponding residues closely interact with one ligand and not the other. In contrast, the fact that some mutations affect both antagonisms may indicate that the corresponding residues are not directly involved in ligand binding but rather are involved in the coupling between binding of the allosteric inhibitor and the transduction to the downstream gating machinery. Another possibility is that some of these residues participate in the formation of the binding "pockets" of both ifenprodil and $\mathrm{Zn}$ (see Discussion).

\section{$\mathrm{Zn}$ and ifenprodil compete for a common binding site on NR1/NR2B receptors}

To examine the nature of the interaction between $\mathrm{Zn}$ and ifenprodil on NR1/NR2B receptors, we took advantage of a distinctive property of the ifenprodil inhibition: its unusually slow dissociation rate. Indeed, whereas current relaxation kinetics observed at the offset of agonists (glutamate and glycine) or at the offset of most NMDA receptor modulators $(\mathrm{Mg}$ or spermine on NR2B-containing receptors, $\mathrm{Zn}$ on NR2A-containing receptors, and protons on native NMDA receptors) are typically in the milliseconds to seconds time scale (Traynelis and Cull-Candy, 1990; Paoletti et al., 1997; Kew and Kemp, 1998; Cull-Candy et al., 2001), full recovery of ifenprodil inhibition requires $>5$ min of wash (Williams, 1993; Kew et al., 1996; Perin-Dureau et al., 2002). Thus, we reasoned that for a population of NR1/ $\mathrm{NR} 2 \mathrm{~B}$ receptors exposed to both $\mathrm{Zn}$ and
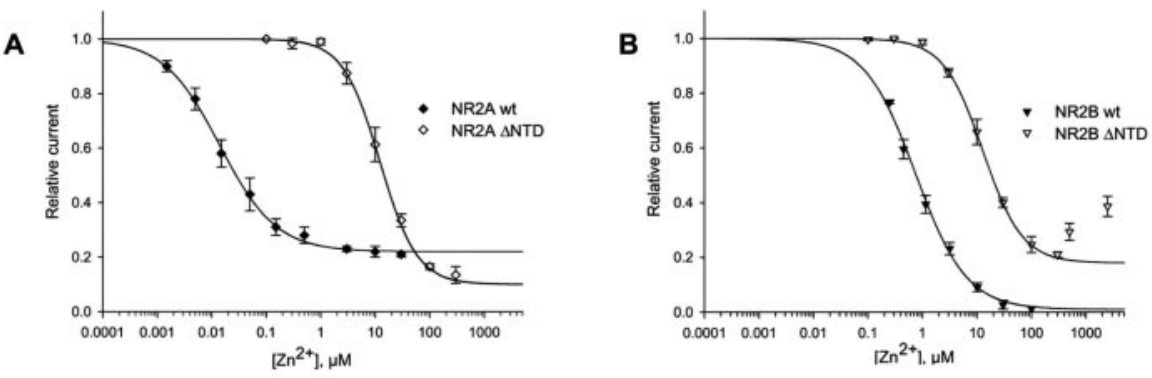

C

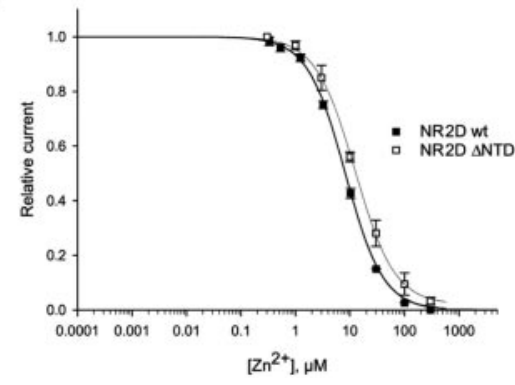

D

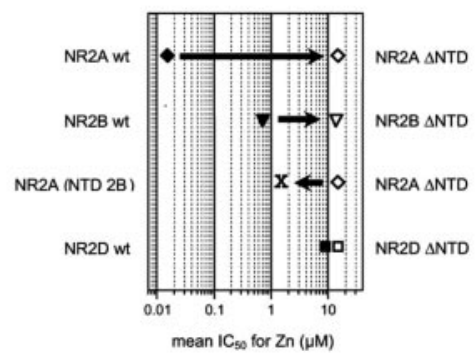

Figure 3. The NTD of NR2B controls Zn inhibition of NR1/NR2B receptors. Comparison of the Zn dose-response curves obtained on NR1/NR2 receptors containing either wild-type or NTD-deleted NR2 subunits is shown. Data were fitted with the Hill equation. Each data point is the mean value from at least three different oocytes. A, Wild-type (wt) and NTD-deleted NR2A-containing receptors. Currents were measured at $+50 \mathrm{mV}$. The estimated values of $\mathrm{Zn} \mathrm{IC}_{50}$ are $16 \mathrm{~nm}$ (wt) and $12 \mu \mathrm{m}(\Delta N T D)$. B, Wild-type and NTD-deleted NR2B-containing receptors. Currents were measured at $+50 \mathrm{mV}$. The estimated values of $Z \mathrm{n} / \mathrm{C}_{50}$ are $760 \mathrm{~nm}$ (wt) and $12 \mu \mathrm{m}(\Delta \mathrm{NTD})$. For this latter construct, data points obtained with Zn concentrations $>100 \mu \mathrm{m}$ were excluded from the fit because $Z n$, in this concentration range, produced an additional potentiating effect. This effect could be attributable to $Z n$ acting on the NR2B-specific Mg/spermine potentiating site (Paoletti et al., 1995). C, Wild-type and NTD-deleted NR2D-containing receptors. Currents were measured at $-60 \mathrm{mV}$ (for NR2D-containing receptors, at this potential and in the tested Zn concentration range, there is no significant contribution of the $\mathrm{Zn}$ voltage-dependent block; see Materials and Methods). The estimated values of Zn IC $\mathrm{C}_{50}$ are $8.4 \mu \mathrm{m}$ (wt) and $12.4 \mu \mathrm{m}$ ( $\Delta$ NTD). D, Effects of NR2 NTD deletions and transplantation on Zn sensitivity. Zn IC values are displayed on a logarithmic scale. Deleting the NTD of NR2A or NR2B strongly affects Zn sensitivity (750-fold and 16 -fold increase in Zn IC ${ }_{50}$ value, respectively), whereas deleting the NTD of NR2D produces very little effect (1.3-fold increase in Zn IC value). Transplanting the NTD of NR2B on the NTD-deleted NR2A subunit [chimera NR2A (NTD-2B)] confers a Zn sensitivity close to that of wild-type NR1/NR2B (IC $C_{50}$ value of $1.45 \mu \mathrm{m}$, maximal inhibition close to 1 ) (Paoletti et al., 2000). Note that all NR2 NTD-deleted receptors display a nearly identical sensitivity to $Z n$, indicating the presence of a remaining low-affinity, voltageindependent and NR2 NTD-independent Zn-binding site common to all receptor subtypes.
A

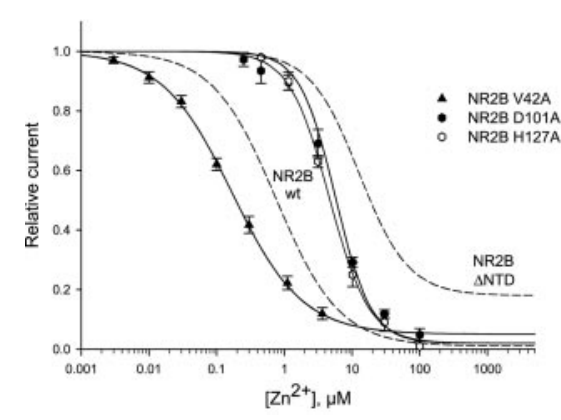

B

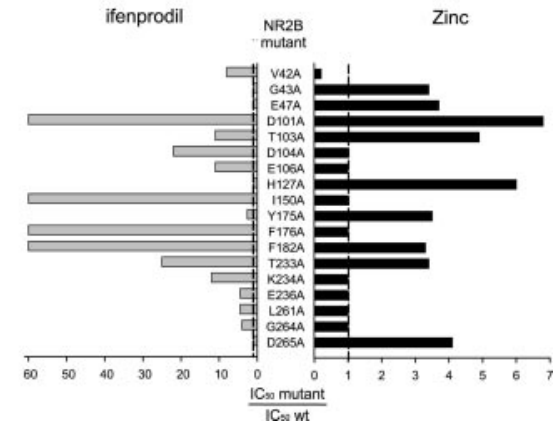

Figure 4. Identifying residues in the NTD of NR2B controlling Zn inhibition of NR1/NR2B receptors. $A$, Zn dose-response curves of NR1/NR2B receptors mutated at positions NR2B-V42, NR2B-D101, and NR2B-H127. Whereas mutations D101A and H127A decrease $Z n$ sensitivity $\left(Z n I_{50}\right.$ value of 5.7 and $4.9 \mu \mathrm{M}$, respectively), mutation V42A increases $Z n$ sensitivity $\left(Z n I_{50}\right.$ value of 0.17 $\mu \mathrm{M}$ ). The dotted curves are the fits of the Zn dose-response curves of wild-type NR1/NR2B receptors (left dotted curve) and NR1/NR2B- $\Delta$ NTD receptors (right dotted curves) obtained in Figure 3 . For NR1/NR2B-V42A receptors, tricine-buffered Zn solutions were used. Each data point is the mean value from at least three different 0ocytes. $B$, Comparison of the effects of NR2B NTD mutants on ifenprodil (left) and $\mathrm{Zn}$ (right) inhibitions quantified as the ratio of the mean $\mathrm{Zn} \mathrm{IC}_{50}$ value for mutant receptors over that of wild-type NR1/NR2B receptors. Listed are all residues that have been identified as critical for ifenprodil (Perin-Dureau et al., 2002) and Zn (present study) inhibitions. Mutations that had no significant effect on Zn or ifenprodil inhibition had ratio values fixed to 1 (dotted lines). Note that some mutations affect either Zn inhibition only or ifenprodil inhibition only, whereas others affect both. 


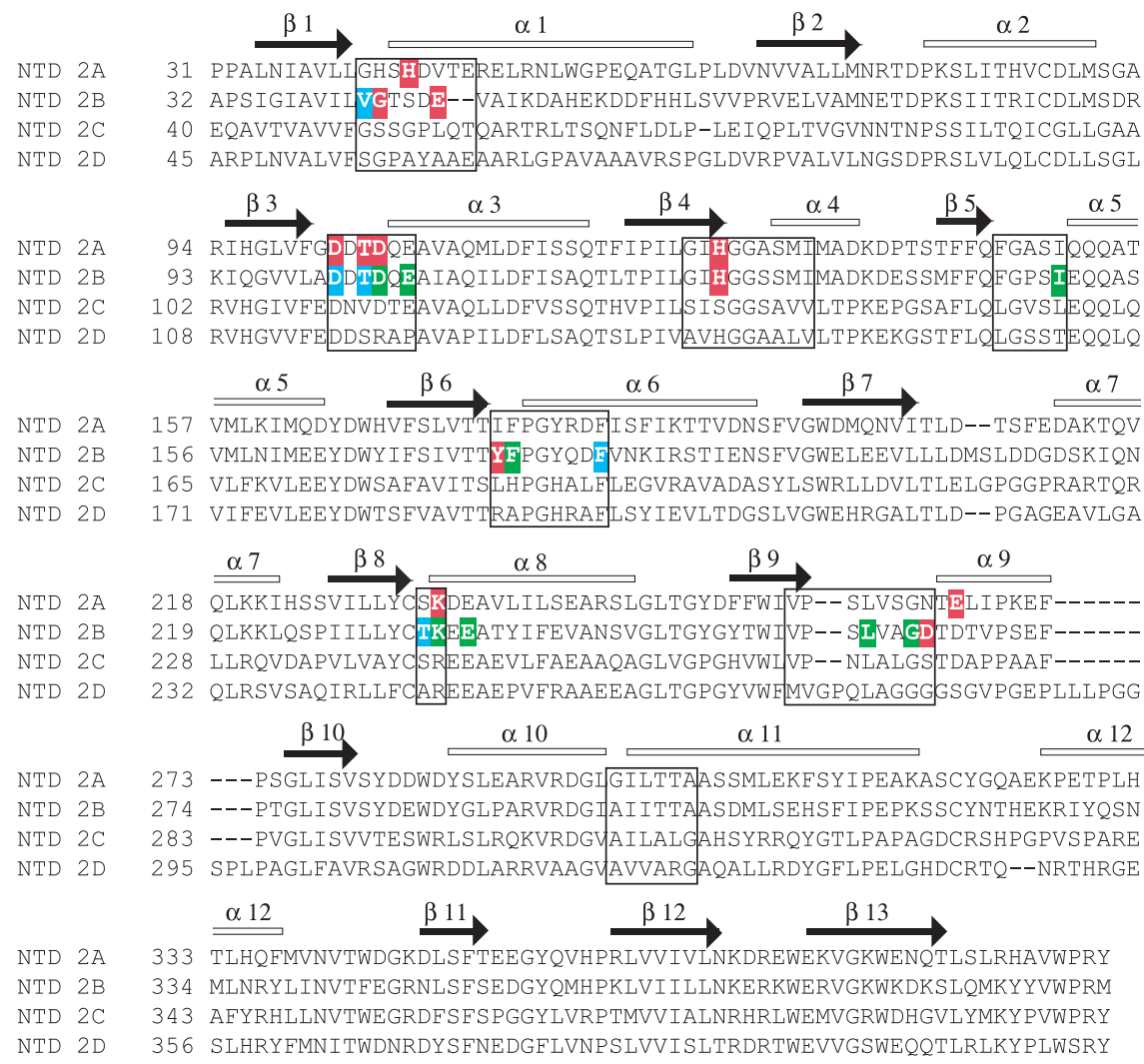

Figure 5. Determinants controlling NR2-specific inhibition of NMDA receptor activity by Zn and ifenprodil. Sequence alignment of all four NR2 subunit NTDs was adapted from Paoletti et al. (2000). Residues of NR2A controlling the high-affinity Zn inhibition are shown in red [T104, a newly identified residue, is highlighted as the mutation $2 \mathrm{~A}-\mathrm{T} 104 \mathrm{~A}$ increases the $\mathrm{Zn}_{\mathrm{IC}} \mathrm{C}_{50}$ value by $>60$-fold ( $n=4)$ ] (P. Paoletti, unpublished data). Residues of NR2B are color-coded as follows: red for those controlling the intermediate-affinity Zn inhibition, green for those controlling ifenprodil inhibition, and blue for those controlling both Zn and ifenprodil inhibitions (see Fig. 4). Mutations of these critical residues all result in a decrease of $\mathrm{Zn}$ and/or ifenprodil sensitivity, except for mutation V42A, which decreases ifenprodil sensitivity but increases Zn sensitivity (see Results). Also note that mutating 2B-Y175 not only affects $Z n$ inhibition but also slightly decreases ifenprodil sensitivity (see Fig. 4). The $\beta$-strands and $\alpha$-helices identified in the structure of the related bacterial protein LIVBP (PDB 2liv) are indicated on top of the alignment; boxes indicate regions (mostly loops) known to contact the ligand molecules in LIVBP-like domains (Paoletti et al., 2000; Perin-Dureau et al., 2002).

ifenprodil, simultaneous washout of both inhibitors should produce a two-phase recovery, with a fast component attributable to Zn dissociation and a slow component attributable to ifenprodil dissociation. The determination of the relative weight of each component would then estimate the proportion of $\mathrm{Zn}$-bound versus ifenprodil-bound receptors.

In a first series of experiments, we compared the off-relaxation kinetics of $\mathrm{Zn}$ and ifenprodil applied separately during an agonist-induced response. As shown in Figure 6, $A 1$ and $A 2$, removal of $\mathrm{Zn}$ (applied at $20 \mu \mathrm{M}$, a nearly saturating concentration) (Fig. 1) led to a much faster recovery than that observed with ifenprodil (applied at $200 \mathrm{nM}$, a concentration close to the $\mathrm{IC}_{50}$ value) (Perin-Dureau et al., 2002). Off-relaxations could be satisfactorily fitted by single exponentials (see Materials and Methods) with estimated time constants $\left(\tau_{\text {off }}\right)$ of $3.3 \pm 1.5 \sec (n=3)$ for $\mathrm{Zn}$ and $54 \pm 6 \mathrm{sec}(n=7)$ for ifenprodil, in close agreement with the value that we had published previously (Perin-Dureau et al., 2002) [note that the observed $\mathrm{Zn}$ off time constant is probably an overestimation of the "true" Zn off time constant because of the limiting rate of solution exchange in our recording chamber $(\sim 2 \mathrm{sec})]$. We then performed a series of experiments in which Zn $(20 \mu \mathrm{M})$ was applied on NR1/NR2B receptors first equilibrated with ifenprodil (200 nM), and off-relaxation kinetics pro- duced after simultaneous removal of both inhibitors were investigated. Inspection of the washout kinetics revealed a biphasic current recovery with the proportion of fast and slow components significantly different depending on the duration of the $\mathrm{Zn}$ application (Fig. 6A3,A4). When $\mathrm{Zn}$ was applied for a short period of time (10 $\mathrm{sec}$ ), the fast and slow component contributed equally to the recovery [fast component: $\tau_{\text {off }}=3.4 \pm 1.4 \mathrm{sec}$, weight $54 \pm$ $3 \%$; slow component: $\tau_{\text {off }}=59 \pm 11 \mathrm{sec}$, weight $46 \pm 3 \%(n=4)]$. In contrast, when $\mathrm{Zn}$ was applied for a much longer period of time ( $8 \mathrm{~min})$, the fast component was clearly dominating [fast component: $\tau_{\text {off }}=3.6 \pm 1.5 \mathrm{sec}$, weight $76 \pm 1 \%$; slow component: $\tau_{\text {off }}=38 \pm 6 \mathrm{sec}$, weight $24 \pm$ $1 \%(n=4)]$. In both cases (short and long protocols), the amount of steady-state inhibition produced by the coapplication of ifenprodil and $\mathrm{Zn}$ is identical: the increased contribution of the fast component in the long protocol relative to the short protocol can only be accounted for by the fact that $\mathrm{Zn}$ ions have displaced ifenprodil molecules during the long application. The requirement for long $\mathrm{Zn}$ coapplications (minutes) is in good agreement with the slow dissociation of ifenprodil being the limiting rate in the process of the re-equilibration of the different inhibitorbound states of the receptors. If these experiments are consistent with $\mathrm{Zn}$ and ifenprodil competing for a common site (with Zn ions replacing ifenprodil molecules), they do not rule out the possibility of an allosteric interaction between two distinct sites, where $\mathrm{Zn}$ could bind ifenprodiloccupied receptors and reduce receptor affinity for ifenprodil. To discriminate between these two possibilities, we performed a similar set of experiments, using the same ifenprodil concentration $(200 \mathrm{nM})$ but a greatly increased $\mathrm{Zn}$ concentration $(300 \mu \mathrm{M}$ instead of $20 \mu \mathrm{M})$. We first verified that when $\mathrm{Zn}$ was applied alone, its washout was fast. This was indeed the case (Fig. 6B1) [fast component only with a $\tau_{\text {off }}=5.1 \pm 1.2$ $\sec (n=3)]$. We then repeated the long $\mathrm{Zn}$ application protocol. Strikingly, after washout of both inhibitors, no slow component could be detected (Fig. 6B2). Off-relaxations could be entirely described with a single component of time constant $4.6 \pm 1.1 \mathrm{sec}$ $(n=3)$, almost identical to the one observed with receptors occupied with $\mathrm{Zn}$ only. Similar results were obtained with $1 \mathrm{~mm}$ $\mathrm{Zn}(n=4$; data not shown). This demonstrates that when $\mathrm{Zn}$ is applied at supra-saturating concentrations and for a long enough amount of time on ifenprodil-occupied receptors, a new equilibrium is reached in which $\mathrm{Zn}$ ions have replaced most ifenprodil molecules. Thus, $\mathrm{Zn}$ and ifenprodil interact in a competitive manner on NR1/NR2B receptors.

\section{Zn binds to the isolated NTD of NR2B}

We have recently developed a simple biochemical assay aimed at testing whether isolated NTDs of NMDA receptors are capable of ligand binding. In this assay, NTDs are first expressed as gluta- 
thione $S$-transferase-tagged proteins in Escherichia coli, solubilized from inclusion bodies, refolded, and finally purified using glutathione-Sepharose beads with thrombin cleavage. Interaction of the isolated domain with a ligand is then assessed by looking at protection against proteolysis conferred after ligand addition. Using this procedure, we previously found that ifenprodil protected the NTD of NR2B against trypsinolysis, whereas $\mathrm{Zn}$, but not ifenprodil, protected the NTD of NR2A (Perin-Dureau et al., 2002). What about $\mathrm{Zn}$ on the NTD of NR2B? As shown in Figure $7 A, \mathrm{Zn}(300 \mu \mathrm{M})$, similarly to ifenprodil $(100 \mu \mathrm{M})$, was very efficient at protecting the isolated NTD of NR2B against digestion by trypsin $(n=6)$. This result implies that the NTD of NR2B forms a Znbinding site. We obtained additional evidence that this domain contains residues closely associated with the NR2B-specific $\mathrm{Zn}$-binding site by reproducing the above experiments using mutated NTDs. Mutations were chosen, according to the functional studies obtained on intact receptors, for their ability to strongly decrease $\mathrm{Zn}$ sensitivity of NR1/NR2B receptors. Mutations were also chosen for their ability to discriminate between the two modulators, $\mathrm{Zn}$ and ifenprodil. Given these criteria, two mutated NTDs of NR2B were produced: NTD-D101A, containing a mutation affecting both $\mathrm{Zn}$ and ifenprodil inhibition, and NTD-H127A, containing a mutation affecting $\mathrm{Zn}$ inhibition only (Fig. 4). As shown in Figure $7 B$, neither $\mathrm{Zn}$ nor ifenprodil were able to protect the mutated NTD-D101A against proteolysis $(n=3)$. In contrast, the mutated NTD-H127A was differentially affected depending on whether $\mathrm{Zn}$ or ifenprodil was used. Although the ifenprodil-induced protection was still present, no protection was seen with $\mathrm{Zn}$ (Fig. $7 C)(n=2)$.

\section{Discussion}

Our main conclusion that the NTD of NR2B contains a Znbinding site is based on multiple findings. The experiments with NR2 NTD truncated or chimeric constructs first show that the NR2B NTD determines Zn potency on NR1/NR2B receptors. The Zn-induced protection of isolated NR2B NTDs against proteolysis provides a direct proof that the NR2B NTD forms a Znbinding site. Moreover, using an alanine mutagenesis scan, we have identified in this domain several residues that control the $\mathrm{Zn}$ sensitivity of NR1/NR2B receptors. It is difficult to deduce from observed changes in $\mathrm{IC}_{50}$ values whether a mutation has affected ligand binding or subsequent conformational changes (or both). However, the fact that some mutations selectively affect $\mathrm{Zn}$ inhibition without affecting ifenprodil inhibition (Fig. 5) rules out a general pertubation of the transduction between the NTD and the gating machinery. Rather, both the location and the chemical nature of the critical residues support a model in which some of
A2

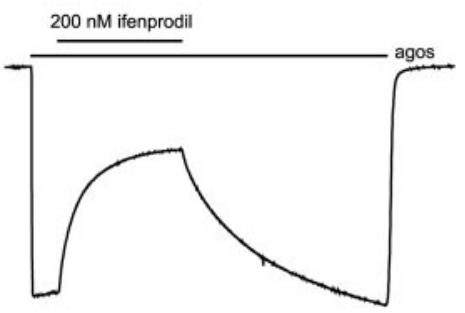

A4

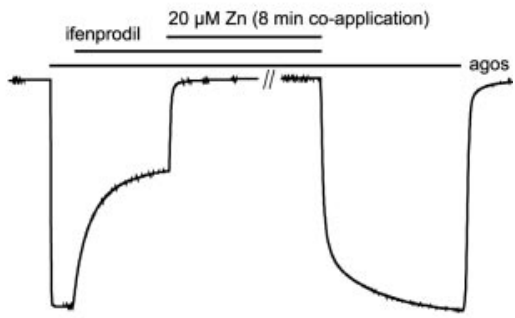

B2

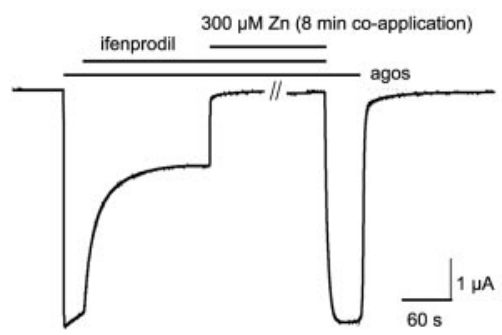

Figure 6. A competitive interaction between Zn and ifenprodil on NR1/NR2B receptors. Off-relaxation kinetics of Zn and ifenprodil applied separately or simultaneously during NMDA responses recorded at $-60 \mathrm{mV}$ on Xenopus 0ocytes expressing wild-type NR1/NR2B receptors are shown. In all experiments, ifenprodil was applied at $200 \mathrm{~nm}$, a concentration close to the $\mathrm{IC}_{50}$ . Zn was applied at two different saturating concentrations, $20 \mu \mathrm{m}$ ( $\sim 25$-fold I $C_{50}$ value) or $300 \mu \mathrm{m}$ ( $\sim 400$-fold I $C_{50}$ value) is applied on receptors first equilibrated with ifenprodil. After simultaneous removal of both antagonists, a fast and a slow

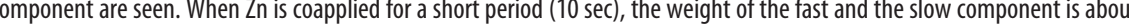
equal. In contrast, when Zn is coapplied for a long period ( $8 \mathrm{~min}$ ), the fast component clearly predominates, indicating that $Z n$ has $\mathrm{min}$ ) removal of both antagonists reveals a (single) fast component of wash only, demonstrating that Zn ions have entirely replaced ifenprodil molecules. Inset, 0ff-relaxations shown on an expanded time scale and after current normalization. Exponential fits are superimposed (dashed white lines) with time constants of $4.1 \mathrm{sec}$ for $Z n$ alone, $59.6 \mathrm{sec}$ for ifenprodil alone, and $3.4 \mathrm{sec}$ for coapplication (8 $\mathrm{min}$ ) of $\mathrm{Zn}$ and ifenprodil.

these residues are closely associated with the $\mathrm{Zn}$-binding site. The rather modest shift in $\mathrm{Zn} \mathrm{IC}_{50}$ values observed with the most effective mutations (D101A and H127A) (Fig. 4) could appear as inconsistent with the direct implication of these residues in $\mathrm{Zn}$ coordination. However, the effect of the mutation on the binding of Zn on the NTD site is probably underestimated because of the presence of another $\mathrm{Zn}$-binding site of lower affinity. The fact that a $\mathrm{Zn}$ concentration as high as $300 \mu \mathrm{M}$ does not protect the mutated NR2B-D101A and NR2B-H127A NTDs against trypsin digestion fully supports this conclusion.

The NR2B NTD Zn-binding site shows striking similarities with the high-affinity $\mathrm{Zn}$-binding site described previously on the NR2A subunit. Both sites map to homologous domains that adopt a similar LIVBP-like bilobate fold (Paoletti et al., 2000) and share two key residues, an aspartate (NR2A-D102 and NR2BD101) and a histidine (NR2A-H128 and NR2B-H127), the mutation of which produce the largest shifts in $\mathrm{Zn}$ sensitivity (Low et al., 2000; Paoletti et al., 2000) (Fig. 4). According to a modeled three-dimensional structure of the NR2B NTD (Perin-Dureau et 
A

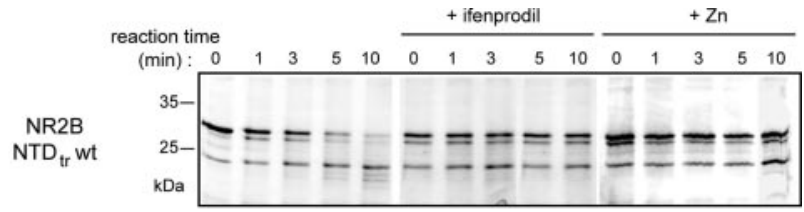

B

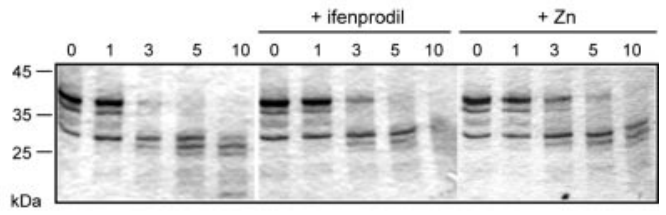

C

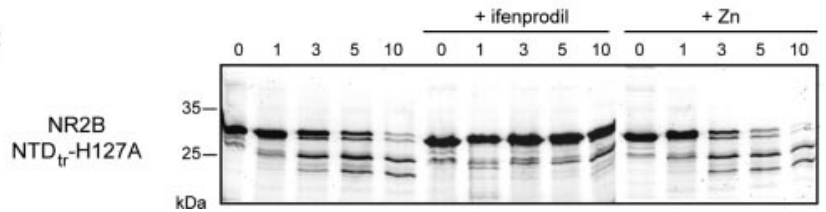

Figure 7. Zn protects the isolated NTD of NR2B against trypsinolysis. Isolated wild-type and mutated NTDs of NR2B were produced in $E$. coli, purified, and subjected to trypsin proteolysis with or without $Z n$ or ifenprodil for various amounts of time (up to $10 \mathrm{~min}$ ). NTDs were produced either as a full-length version (main band at $\sim 40 \mathrm{kDa}$ ) or as a C-terminal truncated (tr) version (main band at $\sim 30 \mathrm{kDa}$ ) (Perin-Dureau et al., 2002). Lane 0 corresponds to the protein solution just before trypsin addition. Ifenprodil was used at $100 \mu \mathrm{M}$, and $\mathrm{Zn}$ was used at $300 \mu \mathrm{M}$. $A$, Wild-type NTD is protected against trypsinolysis by ifenprodil and Zn. B, NTD mutation D101A abolishes protection against proteolysis by either ligand. C, NTD mutation H127A specifically abolishes Zn-induced protection, leaving ifenprodil-induced protection unaffected.

al., 2002), the residues that control $\mathrm{Zn}$ inhibition cluster in two groups (G42, E47, D101, T103, and H127 on lobe 1; Y175A, F182A, T233, and D265 on lobe 2) that face each other across the central cleft. These structural similarities strongly suggest that $\mathrm{Zn}$ interaction with the NTDs of NR2A and NR2B involves a conserved initial mechanism in which Zn would bind in the central cleft and, by interacting with residues from both lobes 1 and 2, promote its closure by a hinge mechanism as seen in other LIVBP-like domains (Quiocho and Ledvina, 1996).

However, there are two important differences between $\mathrm{Zn}$ inhibitions of NR2A- and NR2B-containing receptors. There is first a profound difference in $\mathrm{Zn}$ sensitivities. This could result from a difference in intrinsic $\mathrm{Zn}$ coordination geometry because both the number and the nature of the putative $\mathrm{Zn}$-binding residues differ between NR2A and NR2B (Fig. 5). In particular, the strong influence of D105 and K233 on NR2A Zn sensitivity is not found with the homologous NR2B residues D104 and K234. The difference in Zn potency between NR2A- and NR2B-containing receptors could also reside in differences in the intrinsic equilibrium between the open and closed cleft conformational states. This is best exemplified by a recent study showing that the maltose binding protein (a PBP) can be converted into rationally designed $\mathrm{Zn}$ sensors of variable sensitivity by adjusting both the strength of the $\mathrm{Zn}$ coordination and the "ease" with which the hinge-bending motion occurs (Marvin and Hellinga, 2001).

A second important difference between the $\mathrm{Zn}$ inhibitions of NR2A- and NR2B-containing receptors concerns their $\mathrm{pH}$ dependence. A strong interaction between protons and $\mathrm{Zn}$ has been described at NR1/NR2A receptors (Traynelis et al., 1998; Low et al., 2000). In these receptors, $\mathrm{Zn}$ inhibition is partial (Williams, 1996; Chen et al., 1997; Paoletti et al., 1997), and Traynelis et al. (1998) have shown that the residual current seen at saturating $\mathrm{Zn}$ concentrations depends on $\mathrm{pH}$, such that the maximal $\mathrm{Zn}$ inhibition is significantly higher at acidic pH. In contrast, maximal
Zn inhibition of NR1/NR2B receptors does not seem to be affected by changes in pH (Traynelis et al., 1998; Low et al., 2000) (but see Choi and Lipton, 1999). Such a difference in proton sensitivity of NR2 subunit-dependent $Z n$ inhibitions appears difficult to reconcile with our proposal of a common $\mathrm{Zn}$ inhibition mechanism in both NR2A- and NR2B-containing receptors. However, this apparent discrepancy may have to be reconsidered. Indeed, the high $\mathrm{Zn}$ concentration used in the experiments on NR2B-containing receptors $(15 \mu \mathrm{M})$ opens the possibility that effects specific to the NR2B NTD site may have been masked by the contribution of the low-affinity NR2 NTD-independent Zn inhibition (Fig. 3).

This study and previous work (Perin-Dureau et al., 2002; Malherbe et al., 2003) show that the NR2B NTD is capable of binding two ligands of very distinct chemical nature, the $\mathrm{Zn}$ ion and bis(phenylalkyl)amines such as ifenprodil. Kinetic analysis indicates that $\mathrm{Zn}$ and ifenprodil interact in a competitive manner (Fig. 6). This is in good agreement with the fact that $\mathrm{Zn}$ and ifenprodilbinding sites share a number of structural determinants: D101, T103, F182, and T233 (Fig. 5). Because both Zn and ifenprodil are positively charged, one expects these two ligands to interact with their respective binding pockets through polar/electrostatic interactions [see Tamiz et al. (1998) for a pharmacophore model of the ifenprodil-binding site]. Accordingly, we propose that a central highly polar cluster including D101, T103, and T233 plays a pivotal role in ligand binding by directly interacting with the $\mathrm{Zn}$ ion or with the central basic nitrogen of the ifenprodil molecule. This model is further supported by our biochemical data showing that, although some residues (like H127) specifically control protection of isolated NTDs by one ligand (Zn) but not the other (ifenprodil), other residues (like D101) control both without discriminating. Our conclusion that there is an exclusive occupancy of the NR2B NTD by either Zn or ifenprodil is consistent with observations made on rat brain membranes showing that high $\mathrm{Zn}$ concentrations $(>100 \mu \mathrm{M})$ almost fully displace high-affinity $\left[{ }^{3} \mathrm{H}\right]$ ifenprodil binding (Hashimoto et al., 1994; Nicolas and Carter, 1994; Coughenour and Barr, 2001). NR2B-selective antagonists (ifenprodil being the prototype) are a growing class of compounds with promising therapeutic properties (Kemp and McKernan, 2002). Our results now reveal that their potency will depend on $\mathrm{Zn}$ occupancy of their binding site.

Finally, our results shed a new light on the physiological relevance of the $\mathrm{Zn}$ modulation of NMDA receptors. $\mathrm{Zn}$ is one of the most abundant divalent metal ions in the CNS and is known to be mainly stored in the synaptic vesicles of a subset of glutamatergic synapses where it is coreleased with glutamate during neuronal activity (Frederickson et al., 2000). Although glutamate receptors are the most likely targets of synaptically released $\mathrm{Zn}$, the extent of $\mathrm{Zn}$ modulation of these receptors will greatly depend on the concentrations of $\mathrm{Zn}$ that can be reached after vesicular release. Given the submicromolar Zn sensitivity of NR2B-containing NMDA receptors, elevation of the synaptic $Z n$ concentrations in the low micromolar range would be sufficient for $\mathrm{Zn}$ to act as a potent modulator of these receptors. Current estimates of the levels of synaptically released $\mathrm{Zn}$ indicate that such concentrations are likely to be attained. After strong stimulation in the hippocampus (a structure highly enriched in $\mathrm{Zn}$ ), concentrations as high as $300 \mu \mathrm{M}$ were originally estimated (Frederickson et al., 2000), but these results have been challenged recently by Kay (2003), who reported only nanomolar increase in Zn. A growing number of studies suggest that the actual levels of synaptic $\mathrm{Zn}$ is likely to stand between these two extremes. Studies using $\mathrm{Zn}$ sensitive fluorophores or based on the ability of released $\mathrm{Zn}$ to 

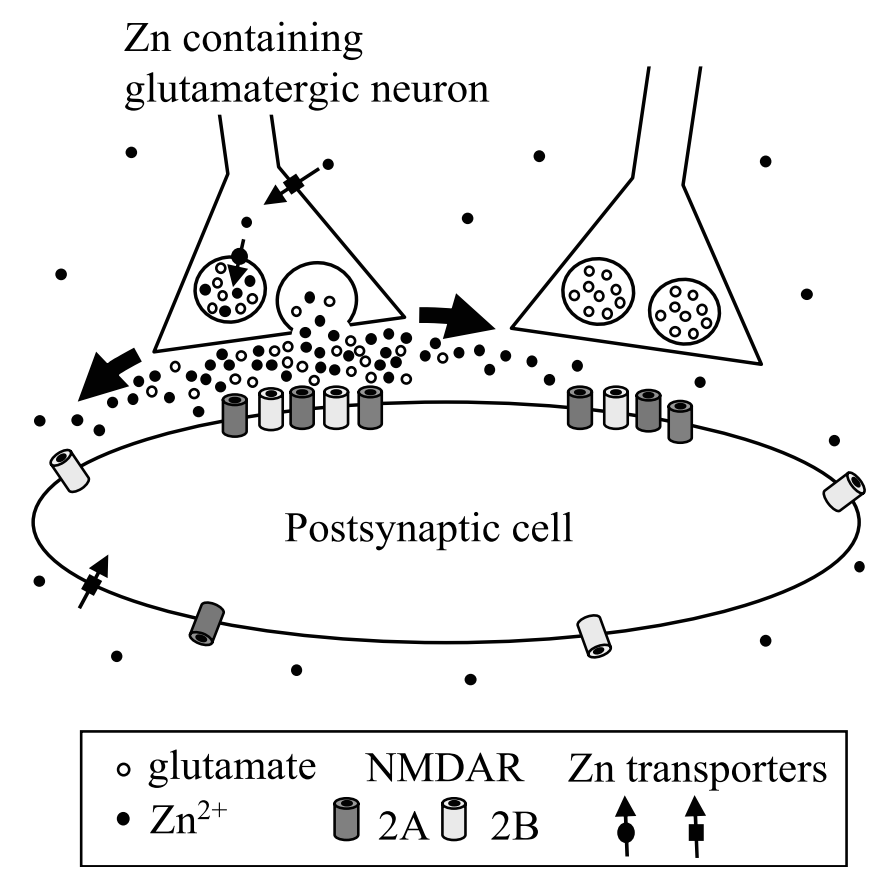

Figure 8. Dual modulation, tonic and phasic, of NMDA receptor activity by extracellular Zn. $\mathrm{Zn}$ is known to be concentrated at many glutamatergic synapses in the CNS. Both transport of Zn into neurons from the extracellular space and into synaptic vesicles have been characterized (Frederickson et al., 2000; Smart et al., 2004). In this model, we propose that ambient Zn levels exert a tonic inhibition of NMDA receptors through binding to the NR2A-specific nanomolar $\mathrm{Zn}$-binding site. During synaptic activity, $\mathrm{Zn}$ is coreleased with glutamate in the synaptic cleft where $Z n$ concentrations are expected to be high enough (micromolar range) to also inhibit the NR2B-specific micromolar Zn-binding site. Thick arrows indicate the possibility that, after phasic liberation, Zn diffuses outside the synaptic cleft. This spillover of Zn could induce inhibition of extrasynaptic NMDA receptors but also of NMDA receptors located at neighboring synapses.

inhibit NMDA receptors resulted in similar estimations in the 5-50 $\mu \mathrm{M}$ range (Vogt et al., 2000; Li et al., 2001; Molnar and Nadler, 2001; Ueno et al., 2002; Smart et al., 2004). If these values are to be trusted, $\mathrm{Zn}$ could be the endogenous ligand of both the NR2A and the NR2B NTDs. Given that NR2A and NR2B are, by far, the most widely expressed NR2 NMDA receptor subunits in the adult brain, $\mathrm{Zn}$ appears to be a key endogenous allosteric modulator of NMDA receptor activity.

Based on our observation that two homologous domains of NMDA receptors form extracellular $\mathrm{Zn}$ sensors of markedly different sensitivities (nanomolar versus micromolar), we propose that $\mathrm{Zn}$ ions in the CNS could provide a dual control, phasic and tonic, of membrane excitability by binding to low- and highaffinity sites on NMDA receptors (Fig. 8). The high Zn sensitivity of the NR2A NTD site might allow ambient Zn levels (in the nanomolar range) (Bogden et al., 1977; Palm and Hallmans, 1982) to inhibit NR2A-containing receptors tonically, while leaving unaffected receptors with lower $\mathrm{Zn}$ sensitivities. In contrast, $\mathrm{Zn}$ released phasically during synaptic activity could reach high levels $(>1 \mu \mathrm{M})$ and inhibit most NMDA receptors present at the synapse, in particular those containing the NR2B subunit. The tonic $\mathrm{Zn}$ modulation of NMDA receptors may be involved in setting the level of background activation of NMDA conductances, which are known to participate in the integrative properties of neurons (Sah et al., 1989). The phasic Zn modulation may provide an efficient way to prevent the harmful consequences of NMDA receptor overactivation. There are two interesting aspects of this model. First, the relative amount of tonic versus phasic $\mathrm{Zn}$ modulation would vary both in time and space: in time, because
NR2A expression starts only after birth, whereas NR2B expression is abundant during embryonic stages; in space, because the relative expression level of NR2A and NR2B varies not only from one brain region to the other but also from one subcellular compartment to the other, and even from one synapse to the other within a single neuron (Cull-Candy et al., 2001). Second, synaptically released $\mathrm{Zn}$ could diffuse to extrasynaptic sites or neighboring synapses (Zn spillover) (Ueno et al., 2002) and, in this latter case, mediate heterosynaptic modulation of NMDA receptors, particularly of the most $\mathrm{Zn}$-sensitive ones (i.e., NR2A containing). This process may allow for experience-dependent $\mathrm{Zn}$ mediated modulation of synaptic plasticity. Finally, the idea of a dual, tonic and phasic, modulation of NMDA receptors by extracellular $\mathrm{Zn}$ could extend to other neurotransmitter receptors, in particular to inhibitory $\mathrm{GABA}_{\mathrm{A}}$ and glycine receptors for which high-affinity (nanomolar) and low-affinity (micromolar) Znbinding sites have also been described previously (Smart et al., 2004).

\section{References}

Armstrong N, Sun Y, Chen GQ, Gouaux E (1998) Structure of a glutamatereceptor ligand-binding core in complex with kainate. Nature 395:913-917.

Ayalon G, Stern-Bach Y (2001) Functional assembly of AMPA and kainate receptors is mediated by several discrete protein-protein interactions. Neuron 31:103-113.

Bogden JD, Troiano RA, Joselow MM (1977) Copper, zinc, magnesium, and calcium in plasma and cerebrospinal fluid of patients with neurological diseases. Clin Chem 23:485-489.

Chen GQ, Cui C, Mayer ML, Gouaux E (1999) Functional characterization of a potassium-selective prokaryotic glutamate receptor. Nature 402:817-821.

Chen N, Moshaver A, Raymond LA (1997) Differential sensitivity of recombinant $N$-methyl-D-aspartate receptor subtypes to zinc inhibition. Mol Pharmacol 51:1015-1023.

Choi YB, Lipton SA (1999) Identification and mechanism of action of two histidines residues underlying high-affinity $\mathrm{Zn}^{2+}$ inhibition of the NMDA receptor. Neuron 23:171-180.

Christine CW, Choi DW (1990) Effect of zinc on NMDA receptor-mediated channel currents in cortical neurons. J Neurosci 10:108-116.

Coughenour LL, Barr BM (2001) Use of trifluoroperazine isolates a $\left[{ }^{3} \mathrm{H}\right]$ ifenprodil binding site in rat brain membranes with the pharmacology of the voltage-independent ifenprodil site on $N$-methyl-D-aspartate receptors containing NR2B subunits. J Pharmacol Exp Ther 296:150-159.

Cull-Candy SG, Brickley S, Farrant M (2001) NMDA receptor subunits: diversity, development and disease. Curr Opin Neurobiol 11:327-335.

Fayyazuddin A, Villaroel A, Le Goff A, Lerma J, Neyton J (2000) Four residues of the extracellular N-terminal domain of the NR2A subunit control high-affinity $\mathrm{Zn}^{2+}$ binding to NMDA receptors. Neuron 25:683-694.

Frederickson CJ, Suh SW, Silva D, Thompson RB (2000) Importance of zinc in the central nervous system: the zinc-containing neurons. J Nutr 130:1471-1483.

Furukawa H, Gouaux E (2003) Mechanims of activation, inhibition and specificity: crystal structures of the NMDA receptor NR1 ligand-binding core. EMBO J 22:2873-2885.

Guan XM, Kobilka TS, Kobilka BT (1992) Enhancement of membrane insertion and function in type IIIb membrane protein following introduction of a ceavable signal peptide. J Biol Chem 267:21995-21998.

Hashimoto K, Mantione CR, Spada MR, Neumeyer JL, London ED (1994) Further characterization of $\left[{ }^{3} \mathrm{H}\right]$ ifenprodil binding in rat brain. Eur J Pharmacol 266:67-77.

Kay AR (2003) Evidence for chelatable zinc in the extracellular space of the hippocampus, but little evidence for synaptic release of Zn. J Neurosci 23:6847-6855.

Kemp JA, McKernan RM (2002) NMDA receptor pathway as drug targets. Nat Neurosci 5:1039-1042.

Kew JN, Kemp JA (1998) An allosteric interction between the NMDA receptor polyamine and ifenprodil sites in rat cultured cortical neurons. J Physiol (Lond) 512:17-28.

Kew JN, Trube G, Kemp JA (1996) A novel mechanism of activity- 
dependent NMDA receptor antagonism describes the effect of ifenprodil in rat cultured cortical neurones. J Physiol (Lond) 497:761-772.

Legendre P, Westbrook GL (1990) The inhibition of a single N-methyl-Daspartate-activated channels by zinc ions on cultured rat neurones. J Physiol (Lond) 429:429-449.

Leuschner WD, Hoch W (1999) Subtype-specific assembly of alpha-amino3-hydroxy-5-methyl-4-isoxazole propionic acid receptor subunits is mediated by their N-terminal domains. J Biol Chem 274:16907-16916.

Li Y, Hough CJ, Suh SW, Sarvey JM, Frederickson CJ (2001) Rapid translocation of $\mathrm{Zn}^{2+}$ from presynaptic terminals into postsynaptic hippocampal neurons after physiological stimulation. J Neurophysiol 86:2597-2604.

Low CM, Zheng F, Lyuboslavsky P, Traynelis SF (2000) Molecular determinants of coordinated proton and zinc inhibition of $N$-methyl-D-aspartate receptors. Proc Natl Acad Sci USA 97:11062-11067.

Malherbe P, Mutel V, Broger C, Perin-Dureau F, Kemp JA, Neyton J, Paoletti P, Kew JN (2003) Identification of critical residues in the amino terminal domain of the human NR2B subunit involved in the RO 25-6981 binding pocket. J Pharmacol Exp Ther 307:897-905.

Marvin J, Hellinga H (2001) Conversion of a maltose receptor into a zinc biosensor by computational design. Proc Natl Acad Sci USA 98:4955-4960.

Mayer ML, Armstrong N (2004) Structure and function of glutamate receptor ion channels. Annu Rev Physiol 66:161-181.

Mayer ML, Vyklicky LJ, Westbrook GL (1989) Modulation of excitatory amino acid receptors by group IIB metal cations in cultured mouse hippocampal neurons. J Physiol (Lond) 415:329-350.

Meddows E, Le Bourdelles B, Grimwood S, Wafford K, Sandhu S, Whiting P, McIlhinney RA (2001) Identification of molecular determinants that are important in the assembly of $\mathrm{N}$-methyl-D-aspartate receptors. J Biol Chem 276:18795-18803.

Moghaddam B (2003) Bringing order to the glutamate chaos in schizophrenia. Neuron 40:881-884.

Molnar P, Nadler JV (2001) Synaptically-released zinc inhibits N-methyl-Daspartate receptor activation at recurrent mossy fiber synapses. Brain Res 910:205-207.

Nicolas C, Carter C (1994) Autoradiographic distribution and characteristics of high- and low-affinity polyamine-sensitive $\left[{ }^{3} \mathrm{H}\right]$ ifenprodil sites in the rat brain: possible relationship to NMDAR2B receptors and calmodulin. J Neurochem 63:2248-2258.

O’Hara PJ, Sheppard PO, Thogersen H, Venezia D, Haldeman BA, McGrane V, Houamed KM, Thomsen C, Gilbert TL, Mulvihill ER (1993) The ligand-binding domain in metabotropic glutamate receptors is related to bacterial periplasmic binding proteins. Neuron 11:41-52.
Palm R, Hallmans G (1982) Zinc concentrations in the cerebrospinal fluid of normal adults and patients with neurological diseases. J Neurol Neurosurg Psychiatry 45:685-690.

Paoletti P, Neyton J, Ascher P (1995) Glycine-independent and subunitspecific potentiation of NMDA responses by extracellular $\mathrm{Mg}^{2+}$. Neuron 15:1109-1120.

Paoletti P, Ascher P, Neyton J (1997) High-affinity zinc inhibition of NMDA NR1-NR2A receptors. J Neurosci 17:5711-5725.

Paoletti P, Perin-Dureau F, Fayyazuddin A, Le Goff A, Callebaut I, Neyton J (2000) Molecular organization of a zinc binding N-terminal modulatory domain in a NMDA receptor subunit. Neuron 28:911-925.

Perin-Dureau F, Rachline J, Neyton J, Paoletti P (2002) Mapping the binding site of the neuroprotectant ifenprodil on NMDA receptors. J Neurosci 22:5955-5965.

Quiocho FA, Ledvina PS (1996) Atomic structure and specificity of bacterial periplasmic receptors for active transport and chemotaxis: variation of common themes. Mol Microbiol 20:17-25.

Sah P, Hestrin S, Nicoll RA (1989) Tonic activation of NMDA receptors by ambient glutamate enhances excitability of neurons. Science 246:815-818.

Smart TG, Hosie AM, Miller PS (2004) $\mathrm{Zn}^{2+}$ ions: modulators of excitatory and inhibitory synaptic activity. Neuroscientist 10:432-442.

Tamiz AP, Whittemore ER, Zhou ZL, Huang JC, Drewe JA, Chen JC, Cai SX, Weber E, Woodward RM, Keana JF (1998) Structure-activity relationships for a series of bis(phenylalkyl)amines: potent subtype-selective inhibitors of $N$-methyl-D-aspartate receptors. J Med Chem 41:3499-3506.

Traynelis SF, Cull-Candy SG (1990) Proton inhibition of N-methyl-Daspartate receptors in cerebellar neurons. Nature 345:347-350.

Traynelis SF, Burgess MF, Zheng F, Lyuboslavsky P, Powers JL (1998) Control of voltage-independent zinc inhibition of NMDA receptors by the NR1 subunit. J Neurosci 18:6163-6175.

Ueno S, Tsukamoto M, Hirano T, Kikuchi K, Yamada MK, Nishiyama N, Nagano T, Matsuki N, Ikegaya Y (2002) Mossy fiber $\mathrm{Zn}^{2+}$ spillover modulates heterosynaptic $N$-methyl-D-aspartate receptor activity in hippocampal CA3 circuits. J Cell Biol 158:215-220.

Vogt K, Mellor J, Tong G, Nicoll R (2000) The actions of synaptically released zinc at hippocampal mossy fiber synapses. Neuron 26:187-196.

Williams K (1993) Ifenprodil disciminates subtypes of the $N$-methyl-Daspartate receptor: selectivity and mechanisms at recombinant heteromeric receptors. Mol Pharmacol 44:851-859.

Williams K (1996) Separating dual effects of zinc at recombinant $N$-methylD-aspartate receptors. Neurosci Lett 215:9-12. 